\title{
Estimativa de produtividade potencial para cana-de-açúcar entre as safras 2014 e 2018 na cidade de Jaciara
}

A cana de açúcar (Saccharum spp.) representa uma parte relevante da economia brasileira no setor do agronegócio. O objetivo deste trabalho foi estimar a produtividade potencial da variedade de cana-de-açúcar RB 835486 de ciclo precoce (11 a 13 meses), cultivada em Jaciara-MT durante os anos de 2014 a 2018.0 método utilizado para obtenção da estimativa desejada baseou-se no da Zona Agroecológica da FAO (MZA). Para os anos estudados, constatou-se que a produtividade estimada das safras 2015/2016 e 2017/2018 apresentaram decréscimo de $71 \%$ e $74 \%$ respectivamente em relação a produtividade real, provavelmente devido à pouca precipitação pluviométrica que afetouo armazenamento de água no solo e consequentemente ocasionou um déficit hídrico maior para estas safras em relação ao demais anos.

Palavras-chave: Rendimento potencial; Método da zona agroecológica; Saccharum spp.

\section{Potential productivity for sugar cane between safes 2014 and 2018 in the city of Jaciara}

\begin{abstract}
Sugarcane (Saccharum spp.) represents a relevant part of the Brazilian economy in the agribusiness sector. The objective of this work was to estimate the potential productivity of the sugarcane variety RB 835486, of early cycle (11 to 13 months), cultivated in Jaciara-MT from 2014 to 2018 . The method used to obtain the desired estimate was based on the FAO Agroecological Zone (MZA). For the years studied, it was found that the estimated productivity of the 2015/2016 and $2017 / 2018$ harvests showed a decrease of $71 \%$ and $74 \%$, respectively, in relation to the real productivity, probably due to the low rainfall that affected the storage of water in the soil and consequently it caused a greater water deficit for these crops compared to other years.
\end{abstract}

Keywords: Potential yield; Agroecological zone method; Saccharum spp.

Topic: Meteorologia, Climatologia e Mudanças Climáticas

Reviewed anonymously in the process of blind peer.
Received: 08/06/2021

Approved: 24/06/2021
Maria da Graça Tomás (ib

Universidade Federal de Mato Grosso, Brasil http://lattes.cnpq.br/0572083694561653

http://orcid.org/0000-0003-4106-9787

mdagraca.tomas@gmail.com

Josimar Brito da Silva (iD

Universidade Federal de Mato Grosso, Brasil

http://lattes.cnpq.br/5521280749112643

http://orcid.org/0000-0002-3137-8853

britoptga@gmail.com

Hellen Lilian Matos da Silva (id

Universidade Federal de Mato Grosso, Brasil

http://lattes.cnpq.br/9304635359092244

http://orcid.org/0000-0001-8251-2867

hellenmattos57@hotmail.com
Paulo Otavio Aldaves dos Santos Guedes

Universidade Federal de Mato Grosso, Brasil

http://lattes.cnpq.br/4165026582376177

http://orcid.org/0000-0001-8423-7715

guedes131090@gmail.com
Referencing this:

TOMAS, M. G.; SILVA, J. B.; SILVA, H. L. M.; GUEDES, P. O. A. S. Estimativa de produtividade potencial para cana-de-açúcar entre as safras 2014 e 2018 na cidade de Jaciara. Revista Ibero Americana de Ciências Ambientais, v.12, n.6, p.212-222, 2021. DOI: http://doi.org/10.6008/CBPC2179-6858.2021.006.0018 


\section{INTRODUÇÃO}

A cana de açúcar (Saccharum spp.) representa uma parte relevante da economia brasileira no setor do agronegócio, sendo atuante no cenário produtivo de açúcares e, principalmente, de biocombustíveis. 0 Brasil se apresenta como maior produtor mundial tendo uma área colhida estimada de 8.589,2 mil hectares e uma área total, entre produção de mudas, área plantada e área colhida de 10.123,5 mil ha, sendo seu principal produtor o Estado de São Paulo (CONAB, 2018).

O segmento sucroalcooleiro no Estado de Mato Grosso começou no século XIX e apesar de não se apresentar como um dos maiores produtores do país obtém uma boa produtividade em pouca área plantada. Isso se deve, principalmente, ao manejo e as boas condições pluviométricas. Na safra 2018/2019 essas condições foram relativamente altas e isso contribui para uma boa produção (CONAB, 2018), uma vez que quando chove mais ocorre uma maior evapotranspiração e, consequentemente, isso pode acarretar em maior produtividade (XAVIER et al., 2016).

Vários fatores podem interferir e condicionar a produtividade e a qualidade da produção (OLIVEIRA et al., 2002), tais como: fatores ambientais (temperatura, luminosidade e umidade do ar e do solo); genéticos e fisiológicos (variedade, idade, tamanho e sanidade das gemas); e fitotécnicos (práticas agrícolas realizadas no campo), precipitação pluviométrica e horas de brilho solar. Em relação a precipitação, não existem factos de tendências significativas, mas existe uma grande variabilidade anual, assim como no padrão espacial das tendências de precipitação (LUCAS et al., 2021).

Fatores climáticas podem provocar impactos significativos nos setores natural, social e econômico (COSTA et al., 1994). Os elementos climáticos mais críticos para a produção agrícola são a temperatura do ar, a radiação solar e a precipitação. A temperatura do ar regula as taxas de desenvolvimento vegetativo e reprodutivo. A radiação solar fornece a energia para a fotossíntese, afetando a partição de carboidratos e o crescimento de componentes individuais da planta. A seca afeta a evapotranspiração, extração de umidade pelas raízes, distribuição do sistema radicular, tamanho da copa e, consequentemente, as taxas de desenvolvimento das plantas (APARECIDO et al., 2018)

Figueiras et al. (2020) ponderam que, as regularidades dos elementos meteorológicos (radiação solar, temperatura do ar e do solo, precipitação, umidade relativa, direção e velocidade do vento, evapotranspiração, déficit e excedente hídrico, armazenamento de água no solo durante o ciclo da cultura) são as principais causas da variabilidade da produção e da qualidade de produtos agrícolas.

Praticamente, todos esses fatores possuem efeito sobre o comportamento fisiológico da cultura em relação ao metabolismo de brotação, perfilhamento, crescimento e desenvolvimento dos colmos, florescimento, maturação e produtividade (MANHÃES et al., 2015).

A cana de açúcar se desenvolve com maior facilidade em lugares com período quente e úmido e ampla radiação solar, sendo que estes fatores condicionam o seu estádio vegetativo, a fase de maturação e colheita, que são períodos onde ocorre a síntese, translocação e alocação de carboidratos para o colmo (SILVA et al., 2014). Quanto menores forem as horas de incidência solar para a cultura, menores serão suas 
taxas de crescimento, devido aos processos fotossintéticos.

Para a produção estimada de cana-de-açúcar vários modelos matemáticos podem ser utilizados como uma ferramenta no planejamento da agricultura, entretanto o modelo agrometeorológico da FAO tem sido o mais recomendado. A metodologia da FAO 48, preconizada pela Organização das Nações Unidas para Alimentação e Agricultura (Food and Agriculture Organization) (FAO, 1978) ou desenvolvida por Kassam (DOOREMBOS et al., 1979), utiliza o princípio do zoneamento agroecológico para estimar a produtividade potencial das culturas em função do clima (TUBIELLO et al., 2007; OLIVEIRA et al., 2012).

O método da Zona Agroecológica (ZAE) permite estimar adequadamente os valores de produtividade da cultura da cana-de-açúcar em função do déficit hídrico relativo, de modo que seja possível verificar os efeitos do tempo e do clima, época e local sobre a produtividade. O modelo tem se apresentado como uma importante ferramenta para estimar a produtividade da cana-de-açúcar em macro escala, podendo auxiliar no planejamento da expansão otimizada da atividade. Esse método pode ser aplicado para previsão de produtividade com eficácia, desde que sejam feitos os ajustes necessários, obtendo-se então resultados satisfatórios (ALMEIDA et al., 2017).

Diante do exposto, o objetivo do presente trabalho foi estimar a produtividade potencial da cultura da cana-de-açúcar, com e sem deficiência hídrica, através de parâmetros climáticos como temperatura, radiação solar e fotoperíodo em diferentes épocas do ano na cidade de Jaciara-MT, seguindo modelos agroecológicos.

\section{MATERIAIS E MÉTODOS}

As variedades analisadas foram provenientes da Usina Porto Seguro, localizada no município de Jaciara - MT nas seguintes coordenadas latitude: 15,95 S, longitude: 54 58' 06" W e altitude: 367m acima do mar. O município de Jaciara, MT apresenta clima tropical, apresentando taxas de pluviosidade média anual de $1750 \mathrm{~mm}$ e temperatura média anual de $24 \% \mathrm{C}$.

As principais variedades cultivadas no local são: RB 867515; RB 928064; RB 835486 e RB 801816 . No presente trabalho considerou-se apenas a variedade RB 835486 que tem ciclo precoce com safra de 11 a 13 meses com plantio iniciado em junho.

Os dados meteorológicos referem-se ao período de 2014 a 2019 e foram obtidos junto ao banco de dados da estação meteorológica convencional da Usina de Porto Seguro em conjunto com o Sistema de Monitoramento Agrometeorológico (AgriTempo). A Tabela 1 contém informações sobre a produção da Usina de Porto Seguro da cidade de Jaciara-MT, no período estudado.

Tabela 1: Produtividade anual (período 5 anos).

\begin{tabular}{llll} 
Ano & TCH & Área (ha) & Produção (Ton.) \\
\hline $\mathbf{2 0 1 4}$ & 52,4 & 18890,77 & 989852,78 \\
$\mathbf{2 0 1 5}$ & 58,59 & 15959,05 & 934984,51 \\
$\mathbf{2 0 1 6}$ & 89,74 & 14051,57 & 1260933,8 \\
$\mathbf{2 0 1 7}$ & 41,78 & 12147,79 & 508444 \\
$\mathbf{2 0 1 8}$ & 55,97 & 8510,76 & 476320 \\
\hline
\end{tabular}

O modelo utilizado para a estimativa da produtividade foi o método da zona agroecológica definido 
pela FAO. Os dados meteorológicos empregados foram temperatura do ar média (ำ) da cultura, precipitação $(\mathrm{mm})$ fornecidas pela AgriTempo, fotoperíodo $(\mathrm{N})$, insolação $(\mathrm{n})$ e radiação solar global (Qo) (MJ $\left.\mathrm{m}^{-2} \mathrm{~d}^{-1}\right)$, os quais foram empregados na estimativa do balanço hídrico climatológico, do balanço hídrico da cultura e da produtividade potencial.

O fotoperíodo $(\mathrm{N})$ e a irradiância solar global extraterrestre $(\mathrm{Q})$ foram estimadas por um autor. $\mathrm{O}$ fotoperíodo $(\mathrm{N})$ é determinado como o intervalo entre o nascer e o pôr do Sol num dado dia, também denominado de duração do dia. Ele é estimado levando em consideração a simetria da trajetória do Sol, sendo igual ao dobro do ângulo horário na hora do Nascer do Sol (hn), ou seja,

$$
\mathrm{N}=2 \mathrm{hn} / 15^{\circ}=0,1333 \mathrm{hn} \text {. }
$$

A irradiância solar global extraterrestre (Qo) foi estimada com base no seguinte cálculo:

$$
Q_{0}=37,6(d / D)^{2}\left[\left(\pi / 180^{\circ}\right) \text { hn sen } \Phi \operatorname{sen} \delta+\cos \Phi \cos \delta \operatorname{sen} h n\right]
$$

$$
(d / D) 2=1+0,033 \cos (\text { NDA } 360 / 365)
$$

Sendo Qo expresso em MJ $\mathrm{m}^{-2}$ dia, a relação d/D representa a distância relativa entre a Terra e o Sol, onde d é a distância média, e $\mathrm{D}$ a distância no dia, hn é a hora do nascer do sol, $\Phi$ representa a latitude e $\delta$ a declinação solar.

$A$ insolação, referente a horas de brilho solar $\left(\right.$ horas $\left.\mathrm{d}^{-1}\right)$, é estimada pela razão $(\mathrm{N} / \mathrm{n})$, onde $\mathrm{N}$ é o fotoperíodo e $n$ a insolação. No caso, pode-se considerar os valores de 0,8 e 0,2 de insolação transmitidas em um dia completamente limpo, e em um dia completamente nublado (LORDER et al., 1984), respectivamente.

\begin{tabular}{|c|c|c|c|c|c|c|c|c|c|c|c|c|}
\hline LAT.(S) & Jan & Fev & Mar & Abr & Mai & Jun & Jul & Ago & Set & Out & Nov & Dez \\
\hline Equador & 12 & 12 & 12 & 12 & 12 & 12 & 12 & 12 & 12 & 12 & 12 & 12 \\
\hline 20 & 12,1 & 12,1 & 12 & 11,9 & 11,9 & 11,9 & 11,9 & 11,9 & 12 & 12 & 12,1 & 12,1 \\
\hline 40 & 12,2 & 12,1 & 12 & 11,9 & 11,8 & 11,8 & 11,8 & 11,9 & 12 & 12,1 & 12,2 & 12,2 \\
\hline 60 & 12,3 & 12,2 & 12 & 11,9 & 11,7 & 11,6 & 11,7 & 11,8 & 12 & 12,1 & 12,3 & 12,3 \\
\hline 80 & 12,4 & 12,2 & 12 & 11,8 & 11,6 & 11,5 & 11,6 & 11,7 & 12 & 12,2 & 12,4 & 12,5 \\
\hline $10^{\circ}$ & 12,5 & 12,3 & 12,1 & 11,8 & 11,5 & 11,4 & 11,5 & 11,7 & 12 & 12,2 & 12,5 & 12,6 \\
\hline $12^{\circ}$ & 12,6 & 12,4 & 12,1 & 11,7 & 11,4 & 11,3 & 11,4 & 11,6 & 11,9 & 12,3 & 12,6 & 12,7 \\
\hline $14^{\circ}$ & 12,7 & 12,4 & 12,1 & 11,7 & 11,3 & 11,2 & 11,2 & 11,5 & 11,9 & 12,3 & 12,7 & 12,8 \\
\hline $16^{\circ}$ & 12,8 & 12,5 & 12,1 & 11,6 & 11,2 & 11 & 11,1 & 11,5 & 11,9 & 12,4 & 12,8 & 12,9 \\
\hline $18^{\circ}$ & 13 & 12,6 & 12,1 & 11,6 & 11,1 & 10,9 & 11 & 11,4 & 11,9 & 12,4 & 12,9 & 13,1 \\
\hline $20^{\circ}$ & 13,1 & 12,6 & 12,1 & 11,5 & 11 & 10,8 & 10,9 & 11,3 & 11,9 & 12,5 & 13 & 13,2 \\
\hline $22^{\circ}$ & 13,2 & 12,7 & 12,1 & 11,5 & 10,9 & 10,7 & 10,8 & 11,2 & 11,9 & 12,5 & 13,1 & 13,3 \\
\hline $24^{\circ}$ & 13,3 & 12,8 & 12,2 & 11,4 & 10,8 & 10,5 & 10,6 & 11,2 & 11,9 & 12,6 & 13,2 & 13,5 \\
\hline $26^{\circ}$ & 13,5 & 12,9 & 12,2 & 11,4 & 10,7 & 10,4 & 10,5 & 11,1 & 11,8 & 12,6 & 13,3 & 13,6 \\
\hline $28^{\circ}$ & 13,6 & 13 & 12,2 & 11,3 & 10,6 & 10,2 & 10,4 & 11 & 11,8 & 12,7 & 13,4 & 13,8 \\
\hline $30^{\circ}$ & 13,7 & 13 & 12,2 & 11,3 & 10,5 & 10,1 & 10,2 & 10,9 & 11,8 & 12,7 & 13,5 & 13,9 \\
\hline $35^{\circ}$ & 14,1 & 13,3 & 12,3 & 11,1 & 10,2 & 9,7 & 9,9 & 10,7 & 11,8 & 12,9 & 13,9 & 14,3 \\
\hline
\end{tabular}

Tabela 2: Duração máxima da insolação diária em horas (n), no $15^{\circ}$ dia de cada mês, em latitudes compreendidas pelo território brasileiro.

A produtividade potencial ou rendimento máximo da cultura $\left(\mathrm{PP}_{\mathrm{R}}\right)$ seguiu o método da Zona Agroecológica da FAO (MZA) apresentado por Doorembos et al. (1994), podendo ser expressa pela fórmula:

$$
\mathrm{PP}_{\mathrm{R}}=\mathrm{PPBP}_{\mathrm{P}} * \mathrm{C}_{\mathrm{IAF}} * \mathrm{C}_{\mathrm{R}} * \mathrm{C}_{\mathrm{COL}} * \mathrm{C}_{\mathrm{UM}} * \mathrm{ND}\left[\mathrm{kg} \mathrm{MS} \mathrm{ha}{ }^{-1}\right]
$$

Em que: PPBp é a produtividade bruta de matéria seca de uma cultura padrão dada em $\mathrm{kg} \mathrm{MS} \mathrm{há-1} \mathrm{d}^{-1} ; \mathrm{C}_{\mathrm{AAF}}$ o coeficiente de correção do índice de área foliar; $C_{R}$ é o coeficiente de correção para a respiração; $C_{C}$ co é o coeficiente de correção para o índice de colheita; Cum é o coeficiente de correção para umidade da parte colhida e ND é o número 
de dias do ciclo da cultura.

A estimativa de produtividade potencial bruta padrão levou em consideração a produção no período de céu claro (PPBC) e a produção no período de céu nublado (PPBn) e pode ser definida como produtividade potencial bruta de matéria seca em kg MS.ha-1 $\mathrm{dia}^{-1}$, considerando a quantidade efetiva de brilho solar.

Esta pode ser expressa pela seguinte equação:

$$
P P B P=P P B n+P P B c\left[M J m^{-2} d^{-1}\right]
$$

Uma das formas de estimar os valores de PPBc e PPBn é apresentada pela equação:

$$
\begin{gathered}
\text { PPBn }=\left(31,7+0,219 \text { Qo) } c T n(1-n / N)\left[M^{-2} \mathrm{~d}^{-1}\right]\right. \\
\text { PPBC }=\left(107,2+0,36 \text { Qo) } c T c n / N\left[M^{-2} \mathrm{~d}^{-1}\right]\right.
\end{gathered}
$$

Em que: Qo é a irradiância solar global extraterrestre expressa em $\mathrm{MJ} \mathrm{m}^{-2} \mathrm{~d}^{-1} ; \mathrm{cTn}$ é a correção devido à temperatura relativa ao período nublado; cTc é a correção devido à temperatura relativa ao período sem nuvens e $\mathrm{N}$ é o fotoperíodo.

A PPB foi determinada pela soma de cTn (fotossíntese bruta padrão em períodos nublados) e cTc (fotossíntese bruta padrão em períodos de sol), considerando que a energia disponível para a fotossíntese muda para cada condição, uma vez que afeta a absorção de energia pelas plantas.

Os coeficientes de correção cTn e cTc variam conforme os grupos da cultura, segundo Dias et al (2017), estes coeficientes estimam a fotossíntese bruta para culturas C 3 ou C 4 e ajusta-a para produção por meio da calibração de coeficientes relacionados ao índice de área foliar (IAF).

Assim, os valores de cTc e cTn foram determinados seguindo Doorembos et al. (1979) e Pereira et al. (2007), e estimados pelas seguintes equações:

$$
\begin{gathered}
\text { Para } \mathrm{T} \geq 16,5^{\circ} \mathrm{C} \\
\text { cTn }=-1,064+0,173 \mathrm{~T}-0,0029 \mathrm{~T}^{2} \\
\text { cTc }=-4,16+0,4325 \mathrm{~T}-0,00725 \mathrm{~T}^{2} \\
\text { Para } \mathrm{T}<16,5^{\circ} \mathrm{C} \\
\text { cTn }=-4,16+0,4325 \mathrm{~T}-0,00725 \mathrm{~T} 2 \\
\text { cTc }=-9,32+0,865 \mathrm{~T}-0,0145 \mathrm{~T} 2
\end{gathered}
$$

O índice de área foliar (IAF) varia conforme o desenvolvimento dos estádios da cultura. Por essa variação, usa-se uma correção em função do índice de área foliar, sendo considerado como padrão para cultura um IAF=5, constante durante todo o ciclo (PEREIRA et al., 2007).

O valor de CIAF é dado pela relação proposta por Pereira et al. (2007):

$$
\text { CIAF = 0,0093 + 0,185 IAFmáx - 0,0175 IAF2 máx (IAFmáx } \geq 5, \text { CIAF = 0,5) }
$$

O coeficiente de correção para a respiração considerado estimado por Pereira et al. (2007) é dado por:

$$
\begin{aligned}
& C_{\text {RES }}=0,6 \text { para } \mathrm{T}<20^{\circ} \mathrm{C} \\
& C_{\text {RES }}=0,5 \text { para } \mathrm{T} \geq 20{ }^{\circ} \mathrm{C}
\end{aligned}
$$

Onde: T é a temperatura média durante o período considerado.

De acordo com Doorembos et al. (1994) e Pereira et al. (2007), para a cultura da cana-de-açúcar $\mathrm{C}_{\mathrm{col}}=$ 0,8 pode ser adotado.

Para se determinar o coeficiente de umidade residual, que fica na matéria seca logo após a colheita, 
é preciso aplicar uma correção e esta é estimada conforme a seguinte equação proposta por Pereira et al. (2007):

$$
\mathrm{C}_{\mathrm{um}}=(1-0,01 * \mathrm{U} \%)-1
$$

Sendo U\% = 80 para a cultura da cana-de-açúcar.

Um dos métodos para saber a deficiência hídrica é estimar utilizar o método do balanço hídrico proposto por usando o modelo de Thornthwaite e Mather (THORNTHWAITE et al., 1995) com uma capacidade de armazenamento de água (CAD) igual a $100 \mathrm{~mm}$ (2008) (ALMEIDA et al., 2017).

E a evapotranspiração da cultura (ETc) calculada multiplicando-se a ETo pelo Kc da FAO a chuva e a evapotranspiração da cultura, calculada de acordo com os valores de Kc para cada estádio fenológico (ALMEIDA et al., 2017). Para estimativa da evapotranspiração da cultura (ETc) utiliza-se:

$$
\mathrm{ETc}=\mathrm{Kc} * \mathrm{ETO}
$$

\section{RESULTADOS E DISCUSSÃO}

A partir da coleta dos dados da precipitação e das condições da região nos períodos de 2013, 2014, 2015, 2016, 2017 e 2018; foi construído o balanço hídrico mensal de cada ciclo da cultura com início em junho e termino em junho do próximo período, para demonstrar a oferta de água em cada ciclo da cultura.

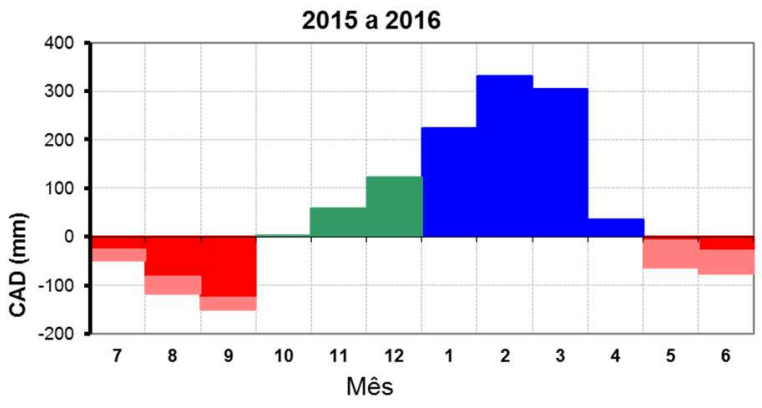

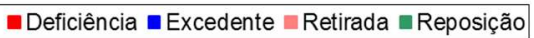

Figura 1: Balanço normal mensal de julho de 2013 a junho de 2014.

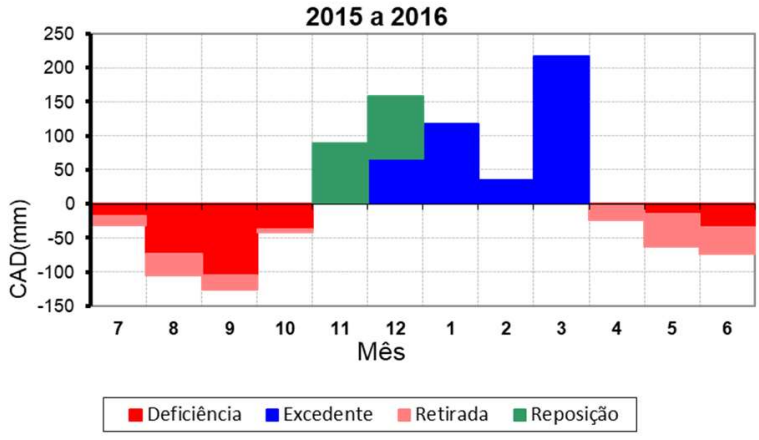

Figura 3: Balanço normal mensal de julho de 2015 a junho de 2016.

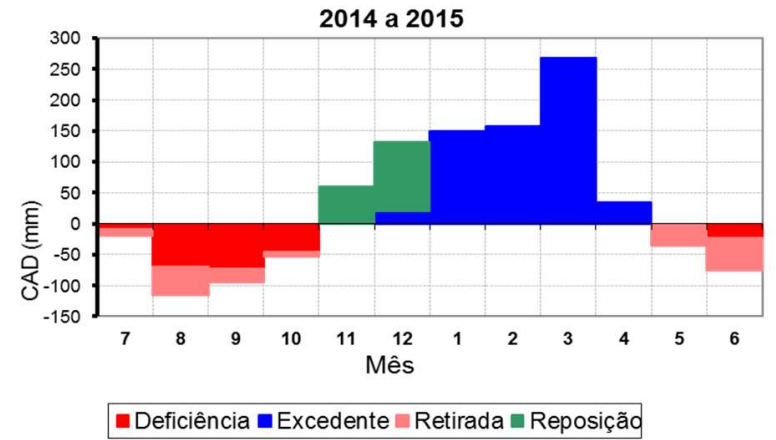

Figura 2: Balanço normal mensal de julho de 2014 a junho de 2015.

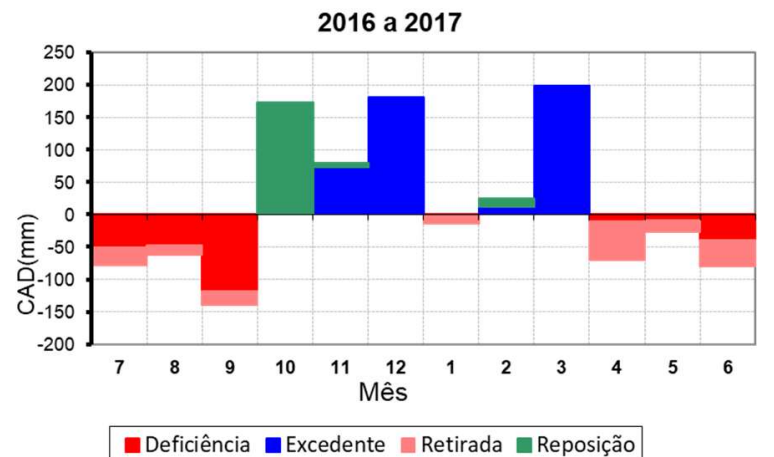

Figura 4: Balanço normal mensal de julho de 2016 a junho de 2017. 


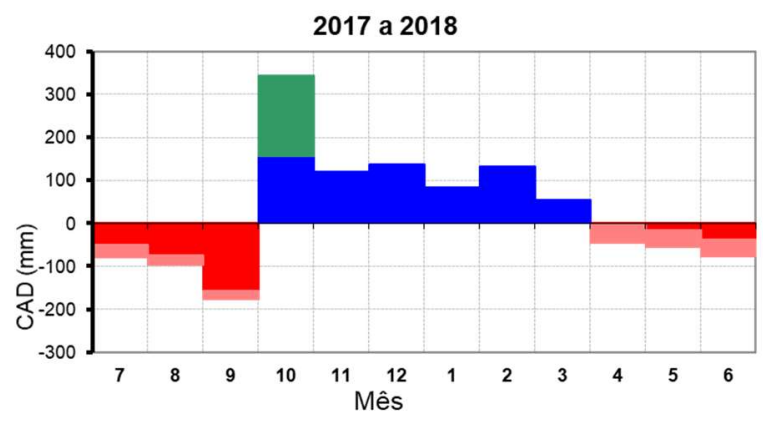

Deficiência Excedente $n$ Retirada $\square$ Reposição

Figura 5: Balanço normal mensal de julho de 2017 a junho de 2018.

Com a oferta de água e os dados do clima no ciclo foi estipulada a ETc, ETr da cultura, sendo que foi analisado a relação entre essas varáveis durante todo ciclo, pois essas variáveis são limitantes para o desenvolvimento dos vegetais.

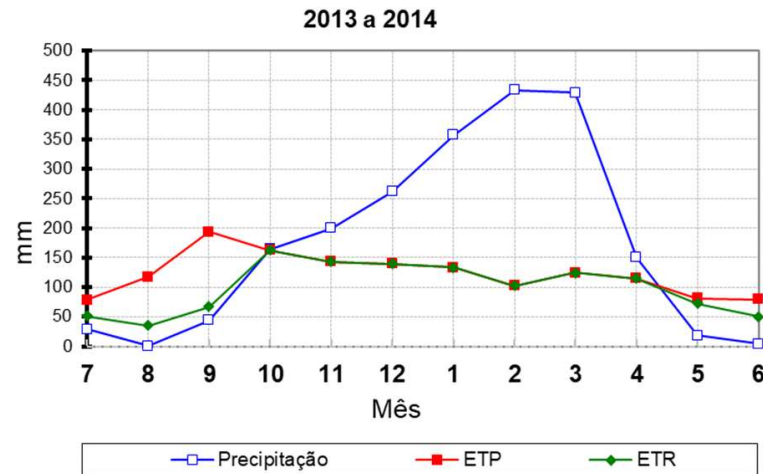

Figura 6: Dinâmica da evapotranspiração no ciclo da cana-de-açúcar nos anos de 2013 a 2014.

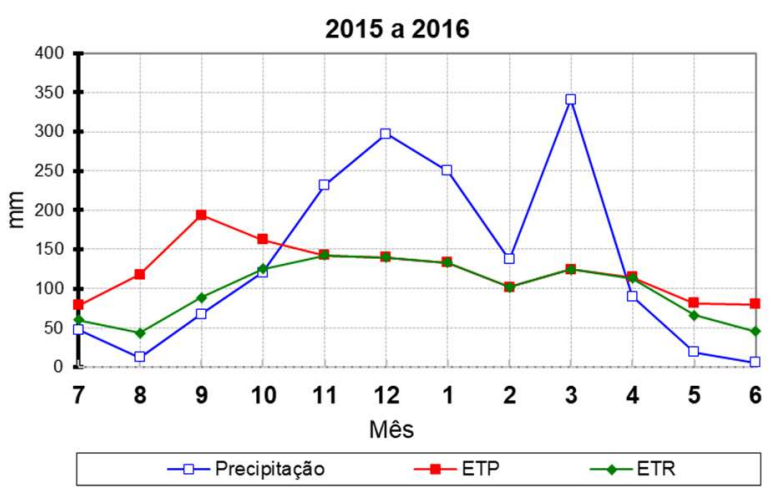

Figura 8: Dinâmica da evapotranspiração no ciclo da cana-de-açúcar nos anos de 2015 a 2016.

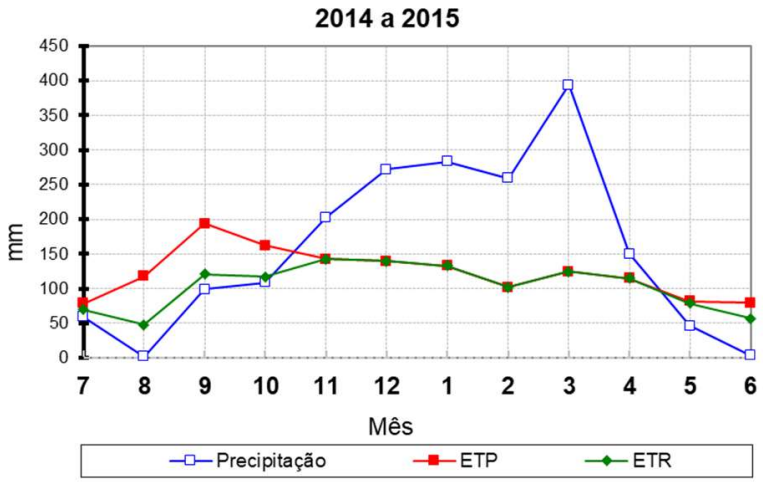

Figura 7: Dinâmica da evapotranspiração no ciclo da cana-de-açúcar nos anos de 2014 a 2015.

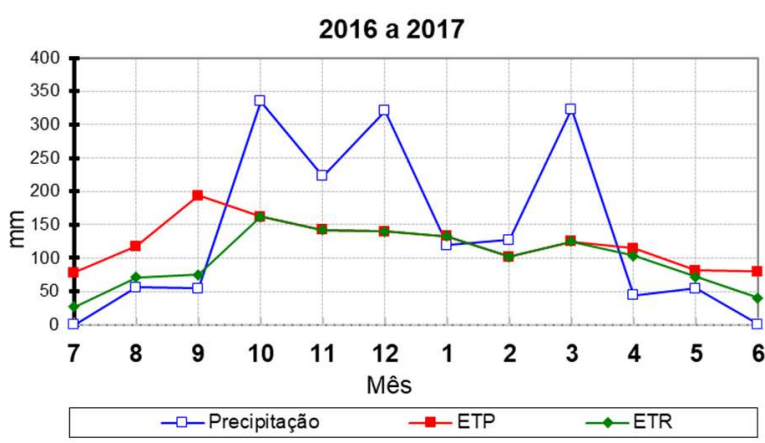

Figura 9: Dinâmica da evapotranspiração no ciclo da cana-de-açúcar nos anos de 2016 a 2017.

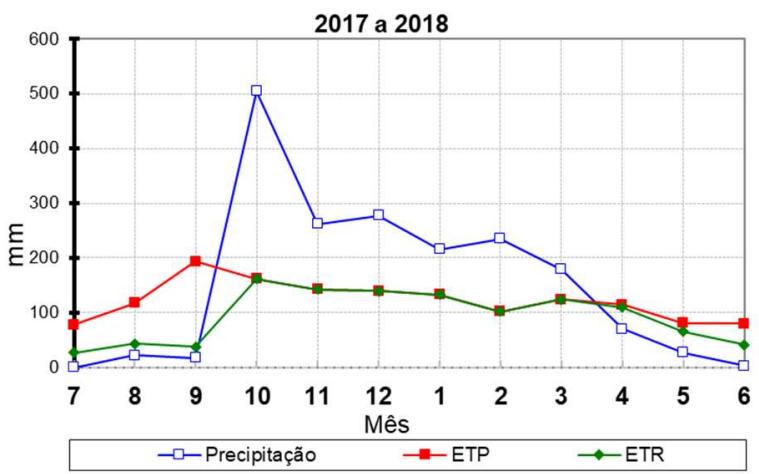

Figura 10: Dinâmica da evapotranspiração no ciclo da cana-de-açúcar nos anos de 2017 a 2018. 
Os dados demonstram os momentos de maior restrição de volume de água onde a cultura tende a ser mais penalizada em sua produção atingível pelo método da Zona Agroecológica da FAO em relação a produção potencial conforme tabela 3.

Tabela 3: Produtividade estimada, produtividade potencial, produtividade real e quebra de produtividade estimada pelo método da Zona Agroecológica da FAO.

\begin{tabular}{|c|c|c|c|c|c|c|}
\hline Ciclo & & $\begin{array}{l}\text { Produtividade } \\
\text { Estimada atingível } \\
\text { (kg.MS.ha }^{-1} \text { ) }\end{array}$ & $\begin{array}{l}\text { Produtividade } \\
\text { Potencial } \\
\text { (kg.MS.ha-1) }^{-1}\end{array}$ & $\begin{array}{l}\text { Quebra } \\
\text { de produtividade } \\
\mathbf{Q}(\%)\end{array}$ & $\begin{array}{l}\text { Produtividade } \\
\text { (kg.MS.ha-1) }\end{array}$ & Real \\
\hline $\begin{array}{l}2013 \\
2014\end{array}$ & a & 66943,4 & 100157,82 & $33,16 \%$ & 52400 & \\
\hline 2015 & & 64213,56 & 102592,24 & $33,40 \%$ & 58590 & \\
\hline $\begin{array}{l}2015 \\
2016\end{array}$ & a & 52396,4 & 103291,84 & $49,27 \%$ & 89740 & \\
\hline $\begin{array}{l}2016 \\
2017\end{array}$ & a & 58201,96 & 101962,65 & $42,91 \%$ & 41780 & \\
\hline $\begin{array}{l}2017 \\
2018\end{array}$ & a & 32071,72 & 102085,89 & $68,58 \%$ & 55970 & \\
\hline
\end{tabular}

Os resultados mostram que na maioria dos ciclos (2013 a 2014, 2014 a 2015 e 2016 a 2017) o modelo superestimou a produtividade das safras demonstrando erros médios de 14,5 Mg ha-1, 5,6 Mg ha-1 e $16,4 \mathrm{Mg}^{-1}$ $\mathrm{ha}^{-1}$ respectivamente. Uma possível justificativa para essa variação pode estar no fato de a produtividade ter sido influenciada por fatores como pragas, doenças e tratos culturais (CAMPOS et al., 2010), que podem variar no tempo e no espaço, afetando, em diferentes níveis, contudo, essas diferenças estão dentro do esperado, quando comparadas com os resultados encontrados por Andrade et al. (2014).

Essa mesma superestimação de produtividade no intervalo de $10-15 \mathrm{Mg} \mathrm{ha}^{-1}$ foi verificada por Tilley et al. (1999) para campos de cana-de-açúcar em Queensland, Austrália.

Segundo Figueira et al. (2020), o déficit hídrico normalmente é o elemento meteorológico que causa mais estresse nas lavouras, reduzindo a produtividade, sendo que a fase de floração costuma ser a mais sensível. Além disso, assegura que a produtividade real (PR) se deve à ocorrência de adversidades meteorológicas (granizo, geada, chuvas fortes, entre outras), insetos-praga, plantas invasoras, baixo nível de tecnologia e investimento dos produtores.

Diferentemente dos anos com produtividade real superestimada, os ciclos de 2015 a 2016 e 2017 a 2018 demonstraram subestimados, onde os resultados acumularam erros médios de $37,3 \mathrm{Mg} \mathrm{ha}^{-1}$ e 23,89 $\mathrm{Mg} \mathrm{ha}^{-1}$ respectivamente, porém, não diferindo do que fora verificado por alguns pesquisadores (OLIVEIRA et al., 2012; ANDRADE et al., 2014).

Entretanto, a produtividade real verificada (89, $\mathrm{Mg}^{\text {ha }}{ }^{-1}$ ) do ciclo 2015 a 2016, manteve-se dentro dos valores encontrados que alcançaram produtividade de 77,6 a $107 \mathrm{Mg} \mathrm{ha}^{-1}$ com variedades em condições de déficit hídricos.

Avaliando a produtividade mínima e máxima da cultura da cana-de-açúcar nas microrregiões de São Paulo, Figueiras et al. (2020), obtiveram resultados de $60 \mathrm{t} \mathrm{ha}^{-1}$ e $95 \mathrm{t} \mathrm{ha}^{-1}$, e sugeriram que o manejo para aumentar a produtividade no campo só pode ser alcançado com a escolha das safras corretas (cultivares adequadas a cada tipo de clima), e densidade de plantio (orientação e escolha da época de semeadura ou plantio correta). 
Para a produtividade real dos ciclos estudados, os padrões de distribuição da produtividade são totalmente diferentes da produtividade potencial, devido aos níveis de déficit hídrico anual observados, concordando com os resultados verificados no Estado de São Paulo.

Em relação à disponibilidade hídrica para o desenvolvimento e produtividade da cana-de-açúcar, ambos os ciclos de cultivo apresentaram maiores excedentes hídricos na primavera-verão (setembro a março). Durante o outono-inverno (abril a agosto), os períodos de déficit hídrico demonstraram semelhantes.

Quanto aos resultados verificados da produtividade real dos demais ciclo de produção, estes demonstraram uma produção mais comprometida e penalizada, devido, principalmente, a restrição de água durante o período inicial dos 120 dias da cultura (Fig. 11, 12 e 13).

2013 a 2014

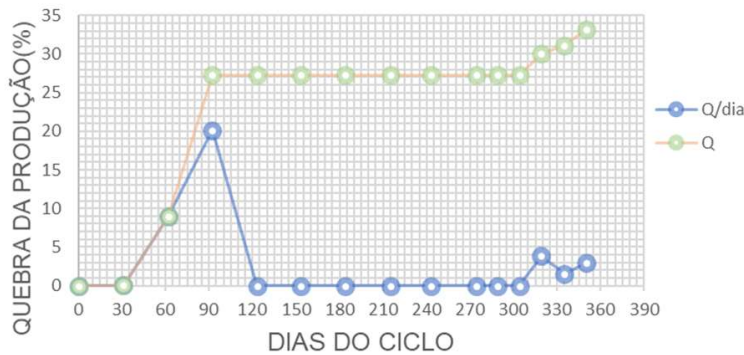

Figura 11: Estimativa de quebra de produção acumulada (Q) da cana-de-açúcar no ciclo e por período (Q/dia) realizado através do método da Zona Agroecológica da FAO nos anos de 2013 a 2014.

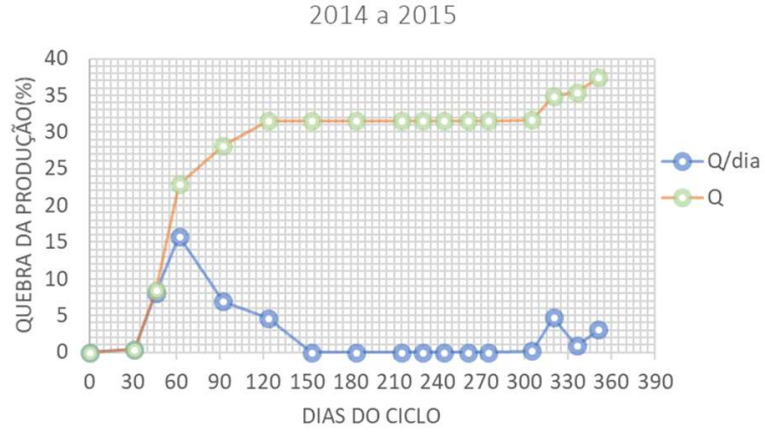

Figura 12: Estimativa de quebra de produção acumulada da cana-de-açúcar no ciclo e por período realizado através do método da Zona Agroecológica da FAO nos anos de 2014 a 2015.

2016 a 2017

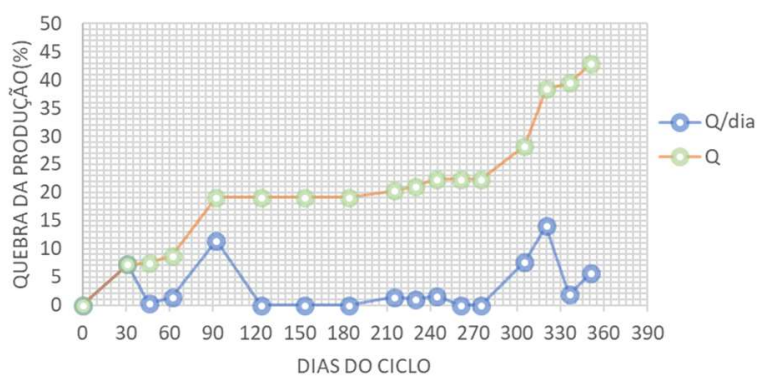

Figura 13: Estimativa de quebra de produção acumulada $(Q)$ da cana-de-açúcar no ciclo e por período ( $Q /$ dia) realizado através do método da Zona Agroecológica da FAO nos anos de 2016 a 2017.

As quebras de produção verificadas devido principalmente o déficit hídrico, concordam com o preconizado em um estudo de 2016, de que diversos estresses climáticos podem afetar áreas agrícolas em várias regiões do planeta.

Marin (2014), afirma que a produtividade média no Brasil é de $60,5 \mathrm{t} \mathrm{ha}^{-1}$, mas que no geral o clima atual permitiria alcançar produtividade de $138 \mathrm{t} \mathrm{ha}^{-1}$ para condições de cultivo com restrições baseadas apenas no estresse hídrico, sem qualquer outra limitação ao crescimento e desenvolvimento da cultura, dado as dificuldades em dissociar influências fisiológicas das do meio físico relacionados com o manejo da cultura.

Com relação à média de $59,69 \mathrm{Mg}$ ha $^{-1}$ da produtividade real dos anos estudados, está demonstra não diferenciar dos intervalos de média de produtividade alcançada em alguns municípios do estado de São Paulo. 
Além disso, fatores como, seca afetando a evapotranspiração, extração de umidade pelas raízes, distribuição do sistema radicular, tamanho da copa e, consequentemente, as taxas de desenvolvimento das plantas, justificam a quebra de produção (APARECIDO et al., 2018).

Todavia, para alguns autores, as variabilidades de solo e clima em diferentes regiões e estações afetam muito o manejo e a produtividade da cultura da cana-de-açúcar, resultando em uma alta heterogeneidade entre os campos de cana-de-açúcar. Essas heterogeneidades são mais evidentes em condições de sequeiro, quando o estresse hídrico pode ocorrer com maior frequência.

Nos ciclos de 2015 a 2016 e 2017 a 2018 o modelo estima perca próxima de 20\% nos dois ciclos a partir dos 250 dias do ciclo da cultura, mas a cultura não apresentou as perdas de produtividade estimadas para essas restrições, respondendo com uma produtividade real maior que a produtividade atingível do modelo nos dois períodos.

2015 a 2016

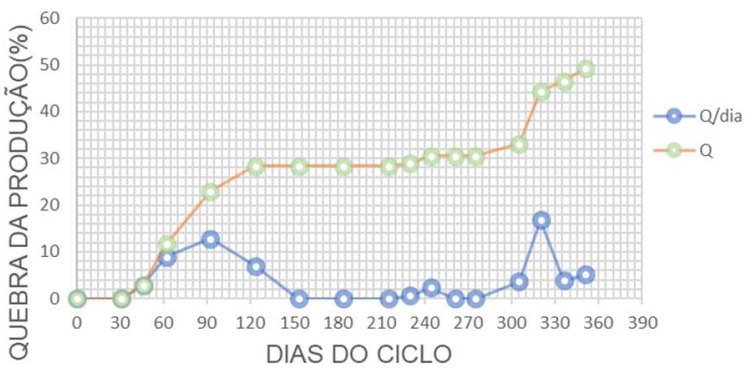

Figura 14: Estimativa de quebra de produção acumulada (Q) da cana-de-açúcar no ciclo e por período (Q/dia) realizado através do método da Zona Agroecológica da FAO nos anos de 2015 a 2016
2017 a 2018

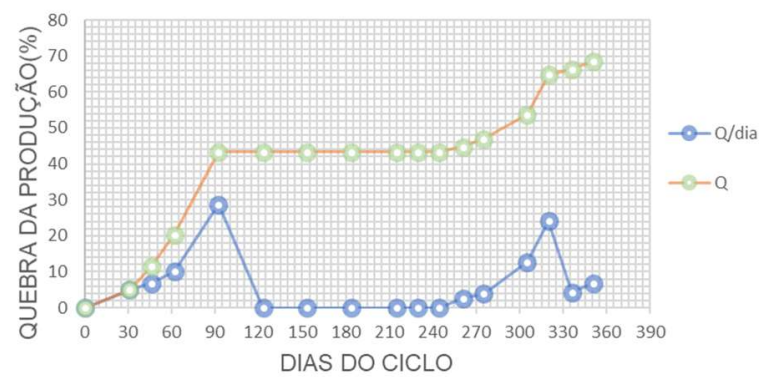

Figura 15: Estimativa de quebra de produção acumulada (Q) da cana-de-açúcar no ciclo e por período (Q/dia) realizado através do método da Zona Agroecológica da FAO nos anos de 2017 a 2018.

\section{CONCLUSÕES}

O método se mostrou uma alternativa válida para as condições supracitadas para estimativas de produtividades para ciclos da cana-de-açúcar que não sejam submetidas a déficit hídrico no período intermediário e final, pois dependendo da cultivar e suas respostas a esses estímulos a produtividade real pode ser maior que a produtividade atingível estimada pelo método da Zona Agroecológica da FAO.

\section{REFERÊNCIAS}

ALMEIDA, T. S.; SEDIYAMA, G. C.; ALENCAR, L. P.. Estimativa da produtividade de cafeeiros irrigados pelo método zona agroecológica espectral. Engenharia na Agricultura, v.25, n.1, p.1-11, 2017.

ANDRADE, R. G.; SEDYAMA, G.; SOARES, V. P.; GLERIANI, J. M.; MENEZES, S. J. M. C.. Estimativa da produtividade da cana-de-açúcar utilizando o sebal e imagens landsat. Revista Brasileira de Meteorologia, v.29, n.3, 433-442, 2014.

APARECIDO, L. E. O.; ROLIM, G. S.. Previsão da produtividade anual do café arábico a partir da deficiência hídrica. Pesquisa Agropecuária Brasileira, v.53, n.12, p.1299-1310, 2018.
CONAB. Companhia Nacional de Abastecimento e Acompanhamento. Safra brasileira de cana-de-açúcar. Brasília: CONAB, 2018

COSTA, M. H.. Balanço hídrico segundo Thornthwaite e Mather de 1995. Viçosa: Universidade Federal de Viçosa, 1994.

DOOREMBOS, J.; KASSAM, A. H.. Efeito da água no rendimento das culturas, Estudos FAO Irrigação e Drenagem. 1979.

DOOREMBOS, J.; KASSAM, A. H.. Efeitos da água no rendimento das culturas. Campina Grande: Universidade Federal da Paraíba, 1994. 
DOOREMBOS, J.; KASSAM, A. H.. Yield response to water. Rome: FAO, 1979.

DOOREMBOS, J.; PRUITT, W. O.. Crop water requirements. Rome: FAO, 1975.

FAO. Food and Agriculture Organization. Reportontheagroecological zones project 48/1-2. Methodologyandresults for África. Results for SouthwestAsia. Roma: FAO, 1978.

LORDER, M. N.; FLUCK, R. C.; MISHOE, J. W.. A method for analysi sugarcane (Sachrum $\mathrm{Sp}$.) biomass production systems. Transactions of the ASAE, St Joseph, v.158, p.146152, 1984.

LUCAS, E. W. M.; SOUZA, F. A. S.; SILVA, F. D. S.; ROCHA JÚNIOR, R. L.; PINTO, D. D. C.; SILVA, V. P. R.. Trends in climate extreme indices assessed in the Xingu river basinBrazilian Amazon. Weather and Climate Extremes, v.31, p.100306, 2021. DOI:

https://doi.org/10.1016/i.wace.2021.100306

MANHÃES, C. M. C.; GARCIA, R. F.; FRANCELINO, F. M. A.; FRANCELINO, H. O.; COELHO, F. C.. Fatores que afetam a brotação e o perfilhamento da cana-de-açúcar. Vértices, Campos dos Goytacazes, v.17, n.1, p. 163-181, 2015. DOI: https://doi.org/10.5935/1809-2667.20150011

MARIN, F. R.. Eficiência de produção da cana-de-açúcar brasileira: estado atual e cenários futuros baseados em simulações multimodelos. Piracicaba, 2014.

OLIVEIRA, M. W.; MENDES, L. C.; BARBOSA, M. H. P.; VITTI, A. C.; FARIA, R. O.. Avaliação do potencial produtivo de sete variedades de cana-de-açúcar sob irrigação complementar. In: REUNIÃO BRASILEIRA DE FERTILIDADE DO SOLO, 25. Anais. Rio de Janeiro: SBCS, 2002.
OLIVEIRA, R. A.; SANTOS, R. S.; RIBEIRO, A.; ZOLNIER, S.; BARBOSA, M. H. P.. Estimativa da produtividade da cana-deaçúcar para as principais regiões produtoras de Minas Geraisusando-se o método ZAE. Revista Brasileira de Engenharia Agrícola e Ambiental, v.16, n.5, p.549-557, 2012. DOI: https://doi.org/10.1590/S1415$\underline{43662012000500011}$

PEREIRA, A. R.; ANGELOCCI, L. R.; SENTELHAS, P. C. Meteorologia Agrícola. Piracicaba: Escola Superior "Luiz de Queiroz", 2007.

SILVA, M. A.; ARANTES, M. T.; RHEIN, A. F. L.; GAVA, G. J. C.; KOLLN, O. T.. Potencial produtivo da cana-de-açúcar sob irrigação por gotejamentoem função de variedades e ciclos. Revista Brasileira de Engenharia Agrícola Ambiental, v.18, n.3, p.241-249, 2014. DOI: https://doi.org/10.1590/S141543662014000300001

THORNTHWAITE, C. W.; MATHER, J. R.. The waterbalance. Centerton: Laboratory of Climatology. Publication of Climatology, v.8, n.1, 1955.

TILLEY, L.; CHAPMAN, L. S.. Benchmarking Crop Water Index for the Queensland Sugar Industry. Brisbane: Escritório de Estações Experimentais de Açúcar e Produtores de Canais, 1999.

TUBIELLO, F. N.; FISCHER, G.. Reducing climate change impacts on agriculture: Global and regional effects of mitigation, 2000-2080. Technological Forecasting \& Social Change, v.74, p.1030-1056, 2007.

XAVIER, A. C.; KING, C. W.; SCANLON, B. R.. Daily gridded meteorological variables in Brazil (1980-2013). International Journal of Climatology, v.36, p.2644-2659, 2016.

A CBPC - Companhia Brasileira de Produção Científica (CNPJ: 11.221.422/0001-03) detém os direitos materiais desta publicação. Os direitos referem-se à publicação do trabalho em qualquer parte do mundo, incluindo os direitos às renovações, expansões e disseminações da contribuição, bem como outros direitos subsidiários. Todos os trabalhos publicados eletronicamente poderão posteriormente ser publicados em coletâneas impressas sob coordenação da Sustenere Publishing, da Companhia Brasileira de Produção Científica e seus parceiros autorizados. Os (as) autores (as) preservam os direitos autorais, mas não têm permissão para a publicação da contribuição em outro meio, impresso ou digital, em português ou em tradução. 